\title{
Review of the genus Thubana Walker (Lepidoptera, Lecithoceridae) from China, with description of one new species
}

\author{
Linlin Yang ${ }^{1, \dagger}$, Yanmei Zhu ${ }^{1,2, \ddagger}$, Houhun $\mathrm{Li}^{1, \S}$ \\ I College of Life Sciences, Nankai University, Tianjin 300071, P. R. China 2 College of Biological Science and \\ Technology, Xinjiang Agricultural and Technical University, Changji 832200, Xinjiang, P. R. China \\ † urn:lsid:zoobank.org:author:E501C3B3-9D64-4982-89A8-12C6F265A923 \\ † urn:lsid:zoobank.org:author:6C9E34A8-69D2-4E20-AD81-CC8279FFE171 \\ § urn:lsid:zoobank.org:author:F6AAB0CO-F312-4035-A08B-3DFE03D02F62 \\ Corresponding author: Houbun Li (lihouhun@nankai.edu.cn)
}

Academic editor: E. van Nieukerken| Received 15 February 2010 | Accepted 23 July 2010 | Published 27 August 2010

urn:lsid:zoobank.org:pub:AA0DC667-9872-462D-89AD-A22F1DC75D26

Citation: Yang L, Zhu Y, Li H (2010) Review of the genus Thubana Walker (Lepidoptera, Lecithoceridae) from China, with description of one new species. ZooKeys 53: 33-44. doi: 10.3897/zookeys.53.412

\section{Abstract}

The genus Thubana Walker is reviewed for China. Nine species are recognized, of which T. felinaurita Li, sp. n. is described as new; T. dialeukos Park, 2003 and T. xanthoteles (Meyrick, 1923) are newly recorded for this country; T. stenosis (Park, 2003), syn. n. is synonymised with T. xanthoteles, and T. microcera (Gozmány, 1978), syn. n. with T. leucosphena Meyrick, 1931. Images of adults and genitalia are provided. A checklist of Thubana species in China is included, along with a key to these species.

\section{Keywords}

Lepidoptera, Torodorinae, Thubana, new species, synonym, China

\section{Introduction}

The genus Thubana was established by Walker (1864) with T. bisignatella Walker, 1864 as the type species. Park and Heppner (2009) listed 46 species in their catalogue of the genus. They included T. laxata (Meyrick, 1911) and T. nodosa (Meyrick, 1910),

Copyright L.Yang et al. This is an open access article distributed under the terms of the Creative Commons Attribution License, which permits unrestricted use, distribution, and reproduction in any medium, provided the original author and source are credited. 
which were once transferred to Stelechoris (Park and Wu 2001), and T. adelella (Walker, 1864), which was earlier removed from the list of Thubana (Park et al. 2005), but did not list T. pedicucullata Park, 2009 and T. gyrostigmatis Park, 2009 from Philippines (Park 2009), and T. reniforma Wu, 2000 from Malaysia (Wu 2000). Here we tentatively add these three species to the list of Thubana.

Prior to this study, seven species of Thubana were recorded in China (Wu 1997). In this paper we describe one new species T. felinaurita Li, sp. n. on the basis of Chinese material, and report T. dialeukos Park, 2003 and T. xanthoteles (Meyrick, 1923) as new for China. We synonymise T. stenosis Park, 2003, syn. n. with T. xanthoteles, and T. microcera Gozmány, 1978, syn. n. with T. leucosphena Meyrick, 1931. To date, the genus Thubana comprizes 48 species worldwide including the new species described herein, and nine of them occur in China.

\section{Material and methods}

Genitalia dissections were carried out following the methods described by Li (2002). All the studied specimens, including the types, are deposited in the Insect Collection, College of Life Sciences, Nankai University, Tianjin, China.

\section{Taxonomic accounts}

\section{Genus Thubana Walker, 1864}

Thubana Walker, 1864: 814. Type species: T. bisignatella Walker, 1864: 814, by original designation.

Titana Walker, 1864: 813. Type species: Titana adelella Walker, 1864: 814, by original designation.

Tiva Walker, 1864: 821. Type species: Tiva binotella Walker, 1864: 822, by original designation.

Inapha Walker, 1864: 999. Type species: Inapha lampronialis Walker, 1864: 999, by original designation.

Stelechoris Meyrick, 1925: 243. Type species: Pachnistis exoema Meyrick, 1911: 707, by original designation.

Diagnosis. Thubana is characterized by the combination of the following characters: forewing often having a white costal patch, costa gently curved with sharpened end, termen more or less concave, tornus broadly rounded, $\mathrm{M}_{3}$ usually stalked with $\mathrm{CuA}_{1+2}$, $\mathrm{R}_{4}$ and $\mathrm{R}_{5}$ often coincident (in some species $\mathrm{R}_{4}$ and $\mathrm{R}_{5}$ stalked basally), $\mathrm{R}_{3}$ stalked with 
$\mathrm{R}_{4+5}$; hindwing with $\mathrm{M}_{2}$ present, almost parallel to stalk of $\mathrm{M}_{3}+\mathrm{CuA}_{1}$; abdominal tergites with spinose zones; valva thumb-shaped, juxta plate-shaped, and aedeagus with diverse cornuti in male genitalia; antrum cup-shaped, ductus bursae usually with many internal spinules, signum with dense spinules in female genitalia.

Thubana is similar to the genus Torodora in the shape of the wings, the presence of $\mathrm{M}_{2}$ on the hindwing, the spined tergites of the abdomen and the structure of male and female genitalia. But Torodora usually lacks the costal patch on the forewing, and $\mathrm{M}_{3}$ is separated with $\mathrm{CuA}_{1+2}$, which can separate the two genera from each other.

Distribution. China, Thailand, Malaysia, Indonesia, Philippines, India, Nepal, Sri Lanka.

\section{Checklist of Thubana species in China}

\section{Thubana albinulla Wu, 1994}

Thubana albinulla Wu, 1994: 130.

Distribution. China (Sichuan).

\section{Thubana albiprata Wu, 1994}

Thubana albiprata Wu, 1994: 130.

Distribution. China (Sichuan).

\section{Thubana albisignis (Meyrick, 1914)}

Lecithocera albisignis Meyrick, 1914: 50.

Thubana albisignis: Meyrick, 1925: 184.

Distribution. China (Taiwan).

\section{Thubana bathrocera Wu, 1997}

Thubana bathrocera Wu, 1997: 86.

Distribution. China (Hunan).

\section{Thubana deltaspis Meyrick, 1935}

Thubana deltaspis Meyrick, 1935: 563.

Distribution. China (Fujian, Taiwan).

\section{Thubana dialeukos Park, 2003}

Thubana dialeukos Park, 2003: 138.

Distribution. China (Yunnan), Thailand. 


\section{Thubana leucosphena Meyrick, 1931}

Thubana leucosphena Meyrick, 1931: 69.

Thubana microcera Gozmány, 1978: 236, syn. n.

Distribution. China (Anhui, Fujian, Jiangxi, Henan, Hunan, Hubei, Guizhou, Zhejiang).

\section{Thubana xanthoteles (Meyrick, 1923)}

Lecithocera xanthoteles Meyrick, 1923: 38.

Lecithocera melitopyga Meyrick, 1923: 41.

Thubana xanthoteles: Clarke, 1965: 232.

Thubana stenosis Park, 2003: 147, syn. n.

Distribution. China (Yunnan), Thailand, India, Sri Lanka.

\section{Thubana felinaurita Li, sp. $\mathbf{n}$.}

Distribution. China (Guangxi).

\section{Key to male Thubana in China}

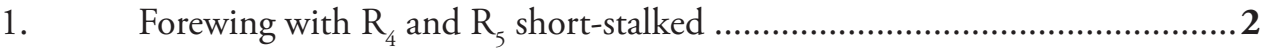

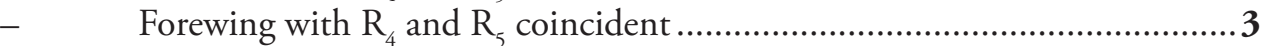

2. Juxta with posterolateral lobes narrowly rounded at apex; aedeagus with two sclerotized bars, the distal one needlelike, the median one acinaciform (Fig. 9) T. xanthoteles

- Juxta with posterolateral lobes acute at apex, aedeagus with two to three dentations near apex (Park 2000: Figs 13, 13a).

T. albisignis

3. Forewing without white patch, with small black cell-dot and fold-dot

T. albinulla

- Forewing with white patch...................................................................

4. Forewing with white basal patch occupying $1 / 3$ of wing, costal patch absent....

T. bathrocera

- $\quad$ Forewing without basal patch, costal patch present

5

5. Male juxta with a long spine at base (Clarke 1965: Figs 2-2b)... T. deltaspis Male juxta without spine at base ............................................................6

6. Aedeagus longer than valva (Fig. 7) ............................. T. felinaurita sp. n.

- $\quad$ Aedeagus shorter than valva .7

7. Juxta without median projection (Fig. 8) ............................... T. dialeukos

- Juxta with median projection ................................................................ 8

8. Juxta with a lobulated projection at middle, with two large thornlike processes on caudal margin; posterolateral lobes inconspicuous (Fig. 15) . T. leucosphena Juxta with a horned projection at middle, without processes on caudal margin; posterolateral lobes mastoid (Wu 1994: Fig. 17) 


\section{Thubana felinaurita Li, sp. $\mathrm{n}$.}

urn:Isid:zoobank.org:act:E86B6559-0A44-44A9-A3CD-62F2D3B8ABCF

Figs 1,7

Type material. Holotype $\widehat{\delta}$ - China, Guangxi Province: Dongzhong Forestry Farm, Fangchenggang, $\left(21^{\circ} 35^{\prime} \mathrm{N}, 108^{\circ} 22^{\prime} \mathrm{E}\right), 640 \mathrm{~m}$, 9.IV.2002, coll. Shulian Hao \& Huai-

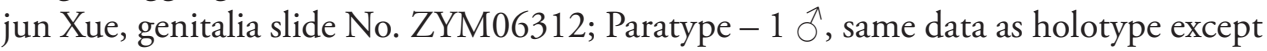
dated 8.IV.2002, genitalia slide No.YLL08061.

Diagnosis. The new species is similar to T. leucosphena, but can be distinguished from it by the juxta having a median membranous protuberance, the posterolateral lobes rounded apically, and the aedeagus longer than valva. In T. leucosphena, the juxta has a lobulate projection at middle near anterior margin and two large thornlike processes on caudal margin, the posterolateral lobes are inconspicuous, and the aedeagus is obviously shorter than the valva.

Description. Adult (Fig. 1). Wingspan 20.5-21.0 mm. Head grayish brown on vertex, with grayish white scales around eyes. Antenna yellowish white, longer than forewing. Labial palpus brown; inner surface of second segment yellowish white mixed with grayish scales; third segment dark fuscous, longer than second. Thorax and tegula grayish brown, with shining luster. Forewing rectangular, costa gently curved, apex blunt, termen slightly concave inward at about $1 / 3$; color brown with dark purple; costal patch triangular, yellowish white, extending to middle of cell; fringe grayish black, with yellowish white basal line. Hindwing grayish brown; fringe fawn black, with yellowish white basal line. Fore leg with dorsal surface dark grayish, ventral surface yellowish white; mid leg yellowish white, with scattered brown scales; hind leg yellowish white on inner surface, grayish brown on outside except tarsus and distal end of tibia yellowish white.

Male genitalia (Fig. 7). Uncus relatively stout, broad basally, narrowed to bluntly rounded apex. Gnathos large, broad in basal $2 / 3$, strongly bent beyond basal 2/3, then narrowed toward apex; apex hooked, greatly curved ventrally. Valva broad at base, slightly narrowed to basal $1 / 3$; distal $2 / 3$ curved upward like a finger, with dense setae on inner surface; apex rounded; costa protruded basally, incurved medially; ventral margin concave inward at basal $1 / 3$, gently arched outward medially. Sacculus weakly sclerotized, broad at base, narrowed distally, straight ventrally, terminating at basal $1 / 4$ length of valva. Juxta quadrate, with a membranous protuberance at middle; posterolateral lobes like cat's ear in shape, setose, rounded posteriorly. Vinculum narrow, weakly sclerotized. Aedeagus very stout, longer than valva, broad in basal 2/5, narrowed toward apex, with caducous setae at apex; vesica slightly sclerotized at base, medially with a bundle of numerous brushlike spines, a slightly arched plate and a slender dentate band.

Female. Unknown.

Distribution. China (Guangxi).

Etymology. The specific name is derived from the Latin felinus (= feline) and auritus (= auricular), referring to the shape of the posterolateral lobes of the juxta. 


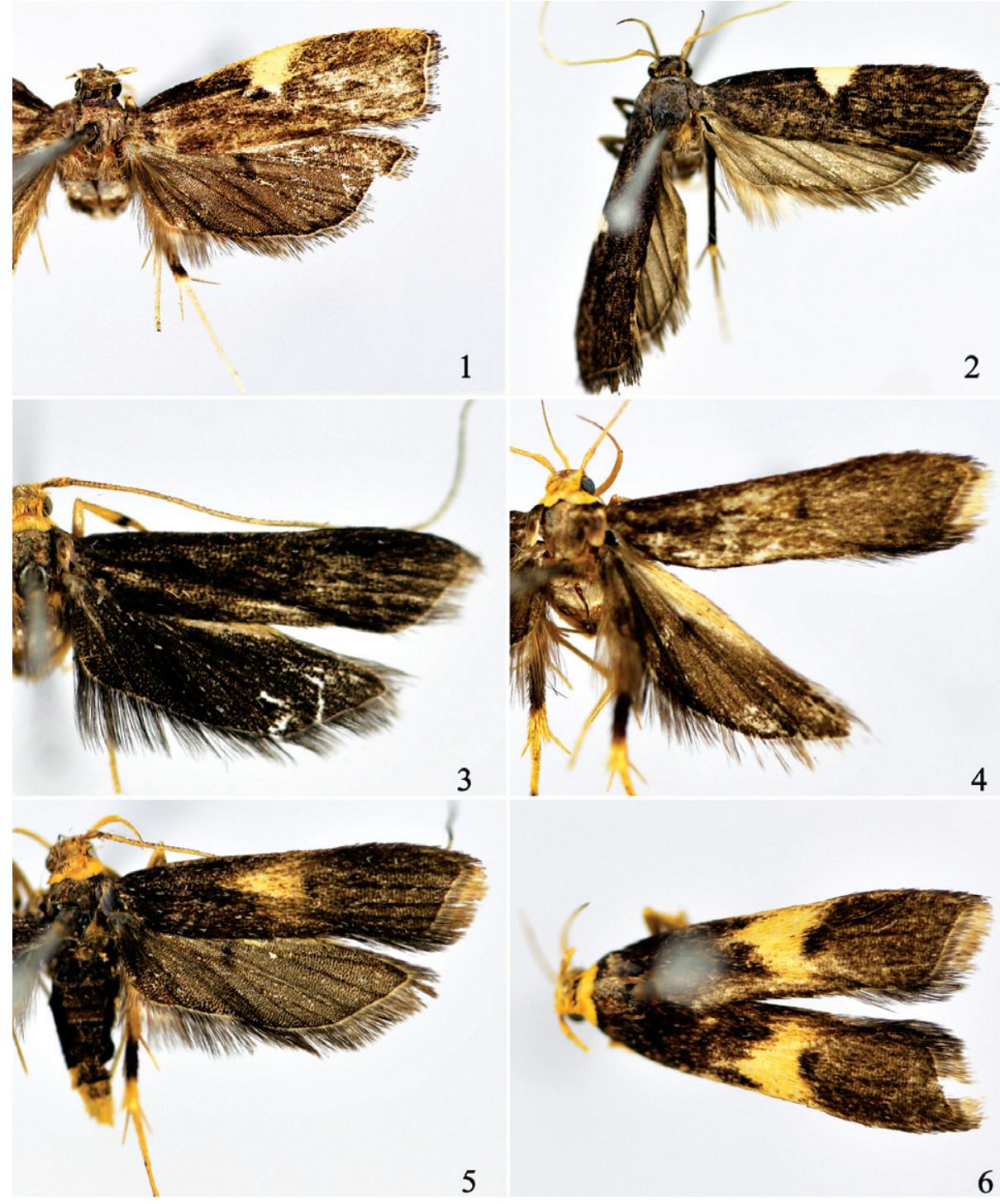

Figures I-6. Adults of Thubana spp. I T. felinaurita sp. n., paratype 2 T. dialeukos Park 3-6 T. xanthoteles (Meyrick), showing variation of costal patch (1-4 Oे, 5-6 ㅇ).

Thubana dialeukos Park, 2003

Figs 2, 8

Thubana dialeukos Park, 2003: 138.

Material examined. $1{ }^{\lambda}$, China, Yunnan Province: Rare Botanical Garden, Ruili $\left(24^{\circ} 00^{\prime} \mathrm{N}\right.$ $\left.97^{\circ} 50^{\prime} \mathrm{E}\right), 1000$ m, 6.VIII.2005, coll. Yingdang Ren, genitalia slide No. YLL08075. 

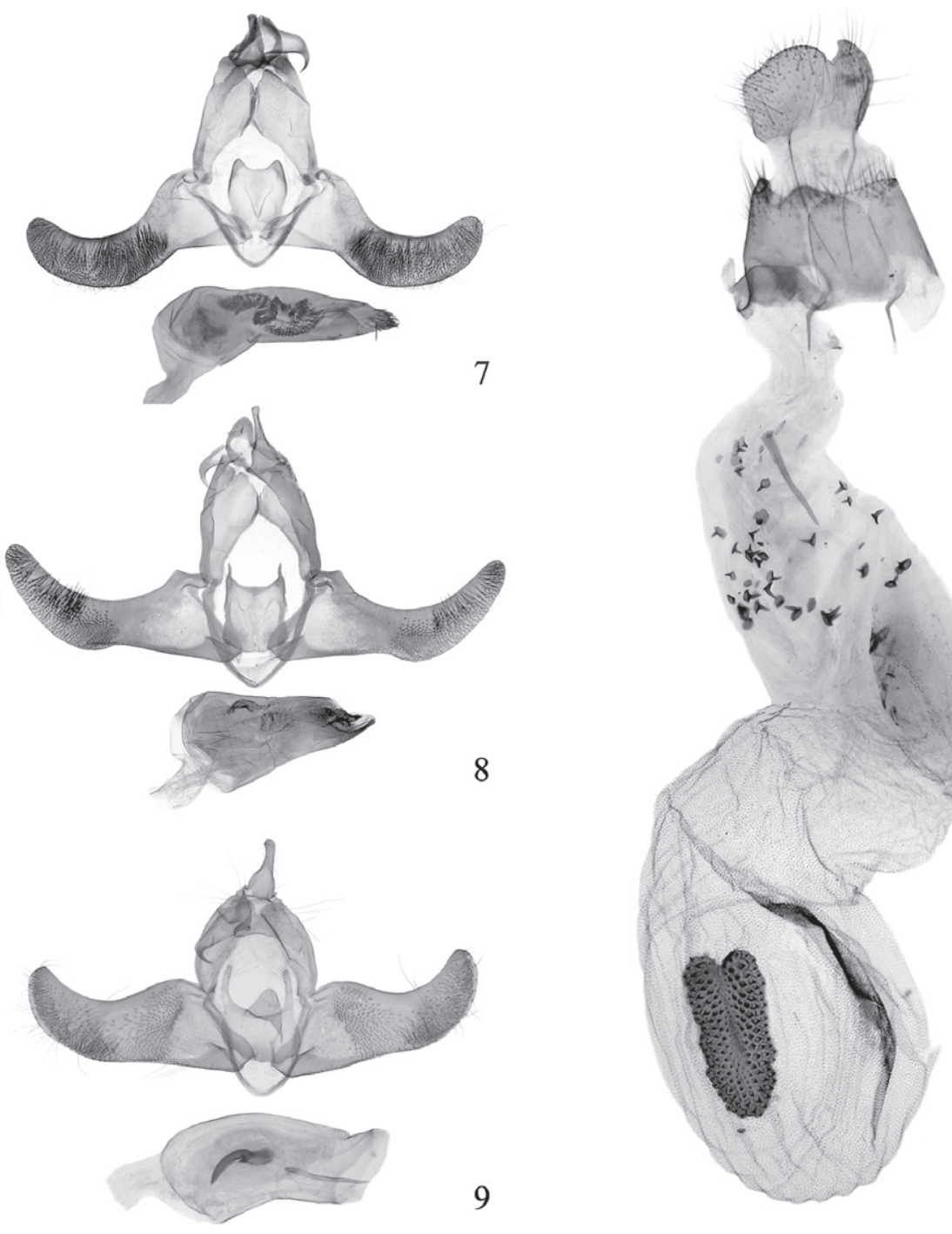

7

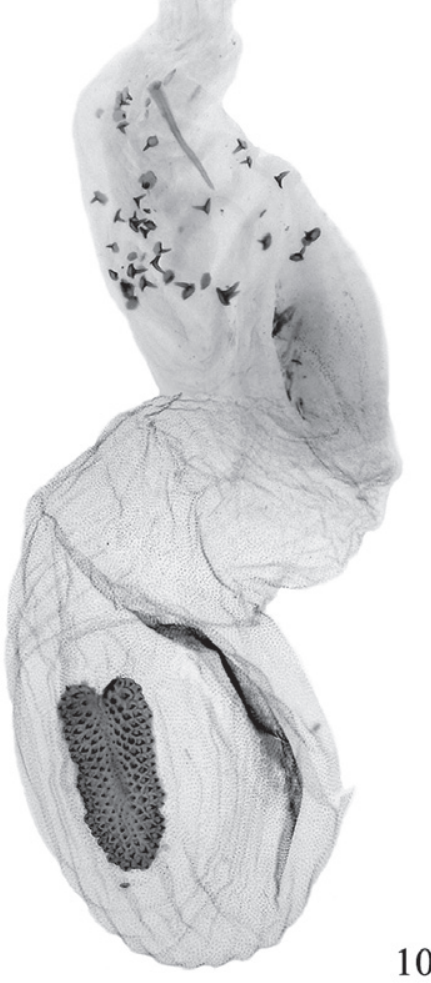

Figures 7-10. Genitalia of Thubana spp. 7 T. felinaurita sp. n., paratype, slide No. YLL08061 $\bigcirc 8$ T. dialeukos Park, slide No. YLL08075 ô 9 T. xanthoteles (Meyrick), slide No. ZYM06119 ô 10 T. xanthoteles (Meyrick), slide No. ZYM06121 ㅇ.

Diagnosis. This species is very close to T. leucosphena and hardly distinguishable from the latter by the superficial characters (Fig. 2) and the venation. However, it can be easily differentiated by the following characters of the male genitalia (Fig. 8): the valva broad at base, narrowed to before middle, gently raising obliquely upward in distal half, narrowed to blunt apex; the costa straight in basal 1/6, gently concave in distal 5/6; the juxta quadrate, with small, slender, almost straight posterolateral lobes; the aedeagus stout, shorter and broader than valva, with two dentate 
preapical lobes, and the cornuti consisting of a S-shaped fragment and a mass of short spines.

Distribution. China (Yunnan), Thailand.

Notes. This species is recorded for the first time from China.

\section{Thubana xanthoteles (Meyrick, 1923)}

Figs 3-6, 9, 10

Lecithocera xanthoteles Meyrick, 1923: 38.

Lecithocera melitopyga Meyrick, 1923: 41; Clarke, 1965: 232, as synonym of Thubana xanthoteles.

Thubana xanthoteles (Meyrick, 1923): Clarke, 1965: 232.

Thubana stenosis Park, 2003: 147, syn. n.

Material examined. $1 \hat{\sigma}, 7$, China, Yunnan Province: Mengla $\left(21^{\circ} 29^{\prime} \mathrm{N} 101^{\circ} 33^{\prime} \mathrm{E}\right)$, $650 \mathrm{~m}, 23-25$.VIII.2005, coll. Yingdang Ren; $2 \mathrm{O}^{\top}, 1$ q , Jinghong $\left(22^{\circ} 01^{\prime} \mathrm{N}, 100^{\circ} 48^{\prime} \mathrm{E}\right)$, 585 m, 17-18.IV.1995, coll. Hongjian Wang \& Guangyun Yan.

Diagnosis. This species can easily be separated from its allies by the elongate narrow forewing without patch (Figs 3, 4), or with an orange-yellow cuneate (Fig. 5) or bandlike costal patch (Fig. 6); in male genitalia (Fig. 9), the juxta with digitate, setose posterolateral lobes and a large triangular median projection, the aedeagus as long as and broader than valva, and the cornuti consisting of two sclerotized bars: the distal one needlelike, about $1 / 2$ length of aedeagus, the median one stouter, somewhat acinaciform; in female genitalia (Fig. 10), the caudal margin of 8th sternite deeply emarginate at middle, the ostium broad, the antrum fan-shaped and weakly sclerotized, the ductus bursae narrowed basally, with many short spines medially, and the signum strawberry-shaped.

Distribution. China (Yunnan), Thailand, India, Sri Lanka.

Discussion. Meyrick (1923) described T. xanthoteles on the basis of two female specimens and described T. melitopyga from one female specimen. Clarke (1965) regarded T. melitopyga as a junior synonym of T. xanthoteles. Thus previously only three female specimens of $T$. xanthoteles have been known and none of these has the costal patch on the forewing. Park (2003) described T. stenosis on the basis of the specimens collected from north Thailand, which bears the "golden yellow bandlike costal patch" on the forewing. He also noticed that the "female genitalia" of T. stenosis "are hardly distinguishable from those of T.xanthoteles". In this study, we found that the male genitalia of the three specimens collected in south Yunnan undoubtedly match with those of $T$. stenosis described by Park, and the female genitalia match with those of T. stenosis and of $T$. xanthoteles. We also found deciduous needlelike cornuti in the ductus bursae of female genitalia. Superficially, the males have no costal patch, but the females usually have a bandlike or cuneate costal patch. Thus we treat T. stenosis as a junior synonym of T.xanthoteles, and regard the presence or absence of the costal patch as intraspecific variation.

Notes. This species is recorded for the first time in China. 


\section{Thubana leucosphena Meyrick, 1931}

Figs 11-16

Thubana leucosphena Meyrick, 1931: 69; Clarke, 1965: 231; Gozmány, 1978: 235; Wu, 1997: 84; Park, 2003: 143.

Thubana microcera Gozmány, 1978: 236, syn. n.

Material examined. China, Zhejiang Province: $13 \hat{\jmath}$, Wuyanling, Taishun $\left(27^{\circ} 33^{\prime} \mathrm{N} 119^{\circ} 42^{\prime} \mathrm{E}\right), 790 \mathrm{~m}, 2-3$. VIII.2007, coll. Qing Jin; 2 ô, 2 ㅇ, same locality, 680 m, 930 m, 28-31.VII.2005, Yunli Xiao; 4 ô, 2 으, Tianmushan $\left(30^{\circ} 26^{\prime} \mathrm{N}\right.$ $\left.119^{\circ} 34^{\prime} \mathrm{E}\right)$, Lin’an, $350 \mathrm{~m}, 7-8$. VIII.2007, coll. Qin Jin, 10 ô, $800 \mathrm{~m}, 19$. VIII.1999,

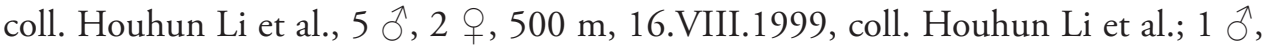
Qingliangfeng $\left(30^{\circ} 07^{\prime} \mathrm{N} 118^{\circ} 51^{\prime} \mathrm{E}\right)$, Lin'an, $900 \mathrm{~m}, 12 . \mathrm{VIII} .2005$, coll. Yunli Xiao. Anhui Province: $40^{\top}$, Mozitan, Huoshuan (31 $\left.24^{\circ} \mathrm{N} 116^{\circ} 19^{\prime} \mathrm{E}\right)$, 12.VIII.2004, coll. Jiasheng Xu \& Jialiang Zhang; $5{ }^{\lambda}$, Huangshan $\left(29^{\circ} 43^{\prime} \mathrm{N} 118^{\circ} 18^{\prime} \mathrm{E}\right), 6-7 . V I I I .2004$, coll. Jiasheng $\mathrm{Xu}$ and Jialiang Zhang; $6 \mathrm{O}^{\top}$, Jiuhuashan $\left(30^{\circ} 23^{\prime} \mathrm{N} 117^{\circ} 48^{\prime} \mathrm{E}\right), 8-9$. VIII.2004, coll. Jiasheng Xu \& Jialiang Zhang. Fujian Province: $2 \AA$, Wuyishan (26 $\left.6^{\circ} 4^{\prime} \mathrm{N} \mathrm{116}{ }^{\circ} 42^{\prime} \mathrm{E}\right), 740 \mathrm{~m}, 19-24 . V .2004$, coll. Haili Yu; 1 ô, Qingyunshan, Yongtai ( $\left.25^{\circ} 52^{\prime} \mathrm{N} 118^{\circ} 57^{\prime} \mathrm{E}\right), 550 \mathrm{~m}$, 18.IX.2002, coll. Xinpu Wang. Jiangxi Provin-

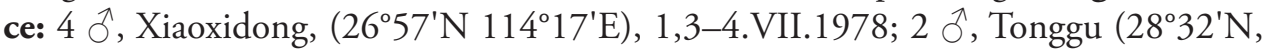

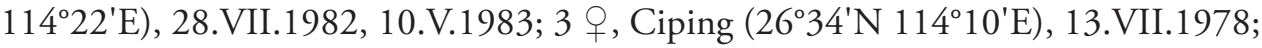
$1 \mathrm{O}^{\top}, 1$ ㅇ, Xiashan, Yichun $\left(27^{\circ} 47^{\prime} \mathrm{N} 14^{\circ} 23^{\prime} \mathrm{E}\right), 7,30 . V I I .1980$; Jinpenshan $\left(29^{\circ} 20^{\prime} \mathrm{N}\right.$ $117^{\circ} 00^{\prime}$ E), 2 Oै, 18-19.VIII.2006, coll. Jiasheng Xu \& Weichun Li. Henan Province: $3{ }^{\circ}, 1$ \% , Xiaguan, Neixiang $\left(33^{\circ} 02^{\prime} \mathrm{N} 111^{\circ} 50^{\prime} \mathrm{E}\right), 650 \mathrm{~m}, 10,12$.VII.1998,

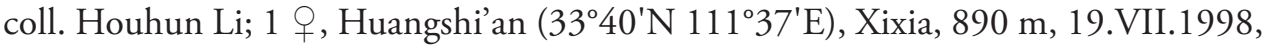

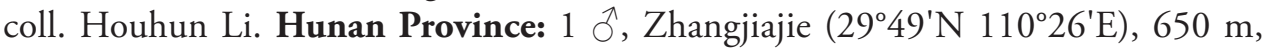
7.VIII.2001, coll. Houhun Li \& Xinpu Wang. Hubei Province: 3 ${ }^{\lambda}, 2$ q, Maoba $\left(30^{\circ} 02^{\prime} \mathrm{N}, 109^{\circ} 02^{\prime} \mathrm{E}\right)$, Lichuan, $700 \mathrm{~m}, 28-29 . \mathrm{VII} .2007$, coll. Houhun Li et al. Guizhou Province: $1 \mathrm{O}^{\top}$, Jiangkou $\left(27^{\circ} 41^{\prime} \mathrm{N} 108^{\circ} 50^{\prime} \mathrm{E}\right), 600 \mathrm{~m}, 27 . \mathrm{VII} .2001$, coll. Houhun Li \& Xinpu Wang.

Diagnosis. This species is characterized by the following characters: male genitalia (Fig. 15) with juxta having a lobulate projection at middle near anterior margin and two large thornlike processes on caudal margin, the posterolateral lobes inconspicuous (Fig. 15b-d), the aedeagus shorter than valva, the cornuti consisting of a long slender band, a bundle of brushlike spines, a dentate plate, and sometimes with a few dispersed deciduous spicules (Fig. 15a); female genitalia (Fig. 16) with apophysis anterioris about $1 / 2$ length of apophysis posterioris, the caudal margin of 8 th sternite slightly emarginate at middle, the ductus bursae long, twisted, with spicules on inner surface (Fig. 16a), and the signum spinulose, semiovate, slightly emarginate at upper margin. Thubana leucosphena is very close to T. felinaurita, but differs as noted in the description of the latter.

Distribution. China (Anhui, Fujian, Jiangxi, Henan, Hunan, Hubei, Guizhou, Zhejiang). 

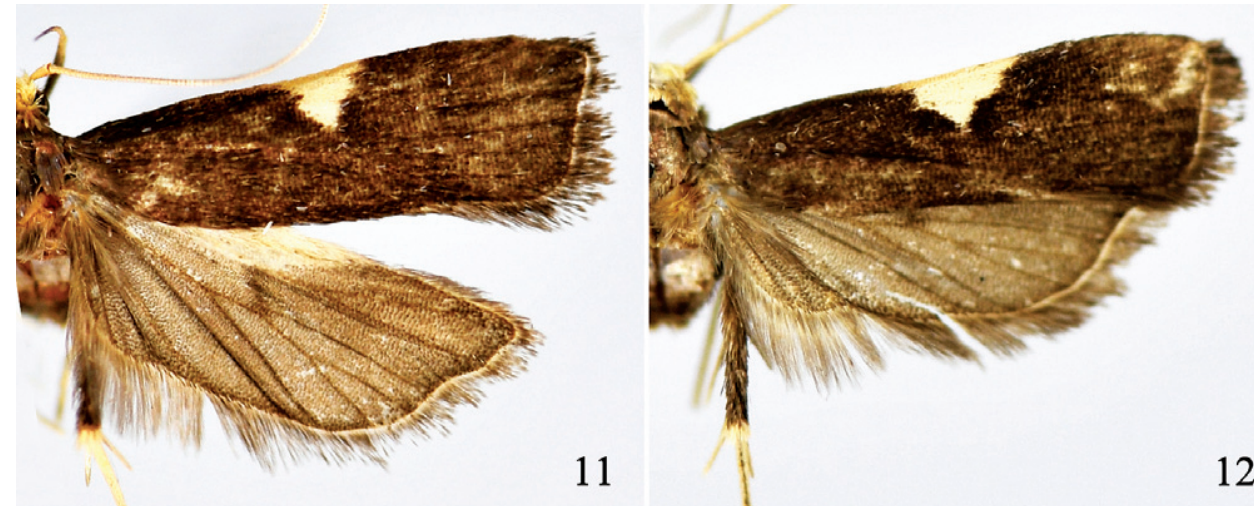

12
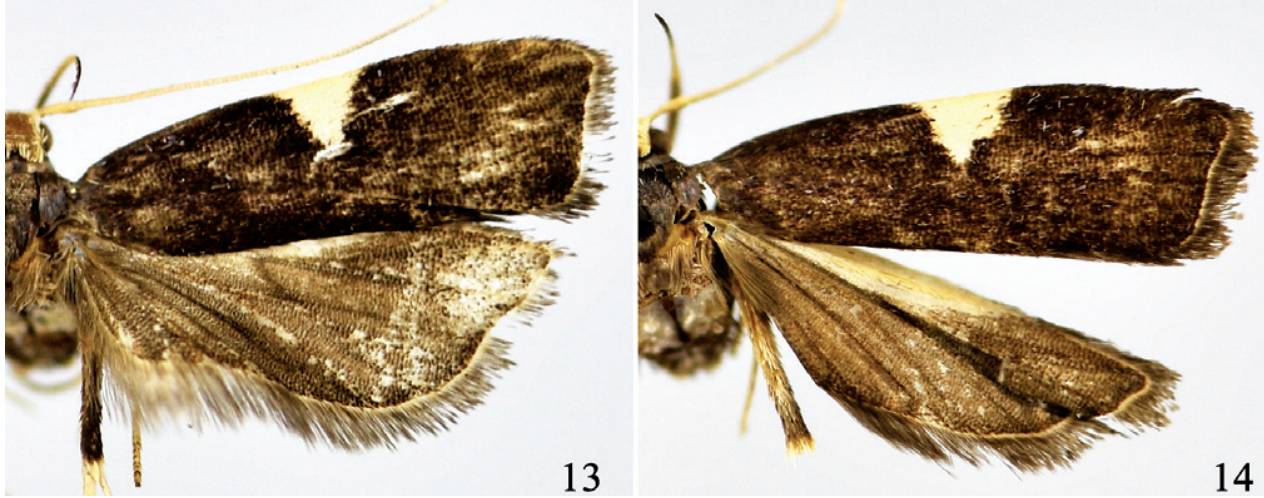

Figures II-I4. Adults of Thubana leucosphena Meyrick, showing variation of costal patch (11-12 $\delta^{7}$, 13-14 ㅇ).

Discussion. This species was described by Meyrick (1931) based on three specimens collected from Guanxian of Sichuan Province in China: "two males" and "a third example". Clarke (1965) rectified the "two males" as Oecophoridae and chose the "third example", a female, as the lectotype of T. leucosphena. Meyrick (1935) mentioned the occurrence of this species in Tianmushan of Zhejiang Province. Gozmány (1978) described T. microcera on the basis of a male specimen collected from Tianmushan and noticed that it could be distinguished from T. leucosphena by the shape of the costal patch. In this study, however, we noticed that the costal patch varies from triangular to trapezoidal both within male specimens of T. microcera (Figs 11-12) and female specimens of T. leucosphena (Figs 13-14). We also found that males collected from Zhejiang, Jiangxi, Hubei and Henan provinces match with those of T. microcera described by Gozmány, females match with those of $T$. leucosphena. Besides, we observed the deciduous spicules from the male aedeagus in the ductus bursae of T. leucosphena. What is more, no other species of Thubana were collected in these localities so far. Hence, we treat $T$. microcera as a junior synonym of $T$. leucosphena, and regard the variation of the shape of costal patch from triangular to trapezoidal as intraspecific variation. 

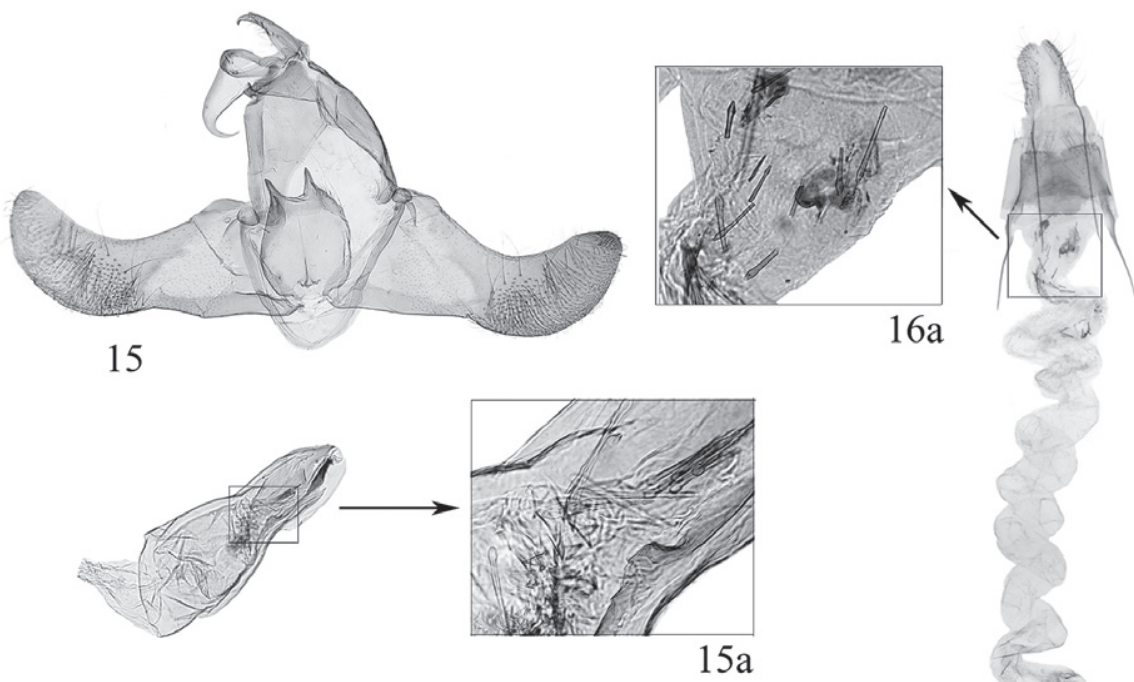

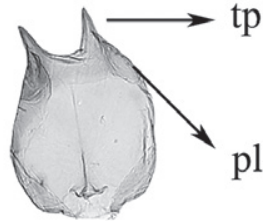

$15 b$

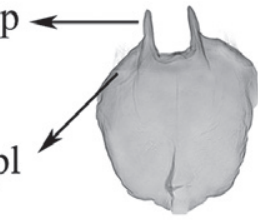

$15 \mathrm{c}$

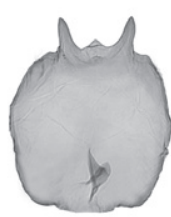

$15 \mathrm{~d}$

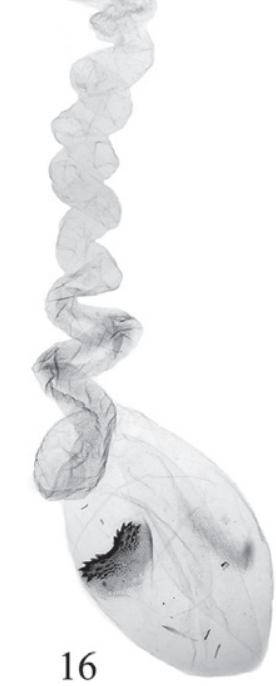

Figures I5-16. Thubana leucosphena Meyrick. 15 male genitalia I5a aedeagus, showing spicules I5bd variation of juxta $(\mathbf{p l}=$ posterolateral lobes, $\mathbf{t p}=$ thornlike processes; slide Nos. b: ZYM06315, c: ZYM06321, d: ZYM06179) I $\mathbf{6}$ female genitalia I6a ductus bursae, showing spicules on inner surface, slide No. ZYM06193.

Notes. The previous description did not mention the median projection on posterior margin of the juxta. Though this projection (Fig. 15b) is not present in most individuals, we found it present in some males, either inconspicuous (Fig. 15c) or small but visible (Fig. 15d). We consider this variation as intraspecific because other characters fit well with T. leucosphaena.

\section{Acknowledgements}

We would like to express our thanks to Yunli Xiao, Haili Yu, Yingdang Ren, Jiasheng Xu, Jialiang Zhang, Weichun Li and Shulian Hao for their efforts in the field. We are also grateful to Dr. K. T. Park for kindly sending us his papers used in species identification. The research was supported by the National Natural Science Foundation of China (No. 30470211). 


\section{References}

Clarke JFG (1965) Catalogue of the type specimens of Microlepidoptera in the British Museum (Natural History) described by Edward Meyrick. Vol. 5. Trustees of the British Museum, London, 228-233.

Gozmány LA (1978) Lecithoceridae. In: Amsel HG, Gregor F, Reisser H (Eds) Microlepidoptera Palaearctica 5. Verlag Georg Fromme \& Co, Wien, 231-237.

Li HH (2002) The Gelechiidae of China (I) (Lepidoptera: Gelechioidea). Nankai University Press, Tianjin, $504 \mathrm{pp}$.

Meyrick E (1910) Description of Malayan Microlepidoptera. Transactions of the Royal Entomological Society of London 1910: 443-447.

Meyrick E (1911) Descriptions of Indian Microlepidoptera. Journal of the Bombay Natural History Society 20: 706-736.

Meyrick E (1914) H. Sauters Formosa-Ausbeute, Pterophoridae-Adelidae (Lep.). Supplementa Entomologica, 3: 45-62.

Meyrick E (1923) Exotic Microlepidoptera 3, E.W. Classey, Hampton, 33-64.

Meyrick E (1925) Family Gelechiadae. In: Wytsman P (Ed) Genera Insectorum. Bruxelles. 184: 1-290, pls. 1-5.

Meyrick E (1931) Second contribution to our knowledge about the Pyralidae and Microlepidoptera of Kwansien. In: Caradja A (Ed) Bulletin de la Section Scientifique de l'Academie Roumaine 14: 68-69.

Meyrick E (1935) Exotic Microlepidoptera 4, E.W. Classey, Hampton, 545-576.

Park KT (2003) Thubana species (Lepidoptera, Lecithoceridae) in Thailand, with descriptions of twelve new species. Journal of Asia-Pacific Entomology 6(2): 137-150.

Park KT, Sugisima K, Abang F (2005) Genus Thubana Walker of the Malaysian Borneo (Lepidoptera, Lecithoceridae), with descriptions of seven new species. Journal of Asia-Pacific Entomology 8(2): 133-141.

Park KT (2009) First record of Thubana species in the Philippines (Lepidoptera, Lecithoceridae), with description of two new species. Journal of Asia-Pacific Entomology 12: 199-201.

Park KT, Heppner JB (2009) Genus Thubana Walker in Indonesia, with descriptions of four new species (Lepidoptera: Lecithoceridae) and a world catalog of the genus. Entomological Science 12: 314-323.

Park KT, Wu CS (2001) Additional faunistic data and discussions of Lecithoceridae (Lepidoptera) from Sri Lanka, with descriptions of seven new species. Insecta Koreana 18(2): 139-152.

Walker F (1864) List of the specimens of the lepidopterous insects in the collection of British Museum. Part XXIX \& XXX, Tineites. British Museum, London, 533-835, 837-1096.

Wu CS (1994) The Lecithoceridae (Lepidoptera) of China with descriptions of new taxa. Sinozoologia 11: 123-154.

Wu CS (1997) Lepidoptera Lecithoceridae. Fauna Sinica, Insecta. 7, Science Press, Beijing, $306 \mathrm{pp}$.

Wu CS (2000) A taxonomic study of the subfamily Torodorinae from Malaysia, with description of three new species (Lepidoptera: Lecithoceridae). Acta Zootaxonomica Sinica 25(4): 426-430. 